\title{
Impact of land use on Costa Rican tropical montane cloud forests: Sensitivity of orographic cloud formation to deforestation in the plains
}

\author{
Deepak K. Ray, ${ }^{1,2}$ Udaysankar S. Nair, ${ }^{1}$ Robert O. Lawton, ${ }^{3}$ Ronald M. Welch, ${ }^{1}$ \\ and Roger A. Pielke Sr. ${ }^{4}$ \\ Received 19 April 2005; revised 24 September 2005; accepted 21 October 2005; published 24 January 2006.
}

[1] The current study provides new insights into the coupling of land use in lowland and premontane regions (i.e., regions below $1000 \mathrm{~m}$ ) and orographic cloud formation over the Monteverde cloud forests. Rawinsondes launched during the Land Use Cloud Interaction Experiment (LUCIE) together with those from the National Centers for Environmental Prediction (NCEP) provided profiles that were used to drive the Colorado State University Regional Atmospheric Modeling System (CSU RAMS) model, which simulated three realistic land use scenarios (pristine forests, current conditions and future deforestation). For current conditions, the model-simulated clouds were compared against those observed at hourly intervals by the Geostationary Environmental Observational Satellite-East (GOES E) satellite. The model performed best on 6 different days. The model-simulated profiles of dew point and air temperatures were compared with the observed profiles from rawinsondes for these days. There was generally very good agreement below $700 \mathrm{mb}$, the region of the atmosphere most crucial to the cloud forests. The average model simulations for the 6 days show that when the lowland and premontane regions were completely forested, the orographic cloud bank intersected the mountains at the lowest elevations, covered the largest land surface area and remained longest on the surface in the montane regions. Deforestation has decreased the cloud forest area covered with fog in the montane regions by around $5-13 \%$ and raised the orographic cloud bases by about $25-75 \mathrm{~m}$ in the afternoon. The model results show that further deforestation in the lowland and premontane regions would lead to around 15\% decrease in the cloud forest area covered with fog and also raise the orographic cloud base heights by up to $125 \mathrm{~m}$ in the afternoon. The simulations show that deforestation in the lowland and premontane regions raises surface sensible heat fluxes and decreases latent heat fluxes. This warms the air temperature and results in a lower dew point temperature of air masses that blow over the lowland and premontane regions. These air masses when lifted form the orographic cloud bank at higher elevations.

Citation: Ray, D. K., U. S. Nair, R. O. Lawton, R. M. Welch, and R. A. Pielke Sr. (2006), Impact of land use on Costa Rican tropical montane cloud forests: Sensitivity of orographic cloud formation to deforestation in the plains, J. Geophys. Res., 111, D02108, doi:10.1029/2005JD006096.

\section{Introduction}

[2] Tropical montane cloud forests (TMCFs), which are characterized by persistent, frequent or seasonal cloud cover at the vegetation level, are biologically rich and diverse as

\footnotetext{
${ }^{1}$ Department of Atmospheric Science, National Space Science and Technology Center, University of Alabama in Huntsville, Huntsville, Alabama, USA.

${ }^{2}$ Department of Forestry and Natural Resources, Purdue University, West Lafayette, Indiana, USA.

${ }^{3}$ Department of Biological Sciences, University of Alabama in Huntsville, Huntsville, Alabama, USA.

${ }^{4}$ Department of Atmospheric Science, Colorado State University, Fort Collins, Colorado, USA.

Copyright 2006 by the American Geophysical Union. 0148-0227/06/2005JD006096\$09.00
}

well as one of the most threatened ecosystems in the world [Hamilton et al., 1993; Doumenge et al., 1995]. Although cloud forests provide habitats for many of the endangered species, most TMCFs are in the mountain ranges as the core of tropical biodiversity "hot spots" that occupy approximately $0.4 \%$ of Earth's land surface while supporting about $20 \%$ and $16 \%$ of Earth's plants and vertebrates respectively [Myers et al., 2000]. Most of these hot spots unfortunately retain less than $25 \%$ of their original primary vegetation covers [Myers et al., 2000] and are continuing to undergo rapid loss of forest cover due to deforestation and climatic changes.

[3] Cloud forests also play important hydrological roles, collecting a significant amount of moisture by direct interception of liquid water from orographic clouds, advected clouds and wind blown mist [Kerfoot, 1968; 
Bruijnzeel and Proctor, 1995; Cavelier et al., 1996]. This process is usually termed horizontal precipitation in the literature. Horizontal precipitation can account for a significant portion of the total precipitation in cloud forests. Data collected from various cloud forest locations around the world show that horizontal precipitation can account for up to $14-18 \%$ and $15 \%-100 \%$ of total precipitation during the wet and dry seasons, respectively [Bruijnzeel and Proctor, 1993]. Therefore destruction of cloud forests could result in decreased streamflows and groundwater fluxes [Meher-Homji, 1991]. For example, measurements from areas in Sri Lanka, where cloud forests have been converted to tea estates, show decreases in streamflow without accompanied decline in precipitation [Doumenge et al., 1995]. Epiphytes such as moss and ferns act like sponges soaking up precipitation during the rainy season and slowly releasing it during the dry season. They also provide protection against flooding and soil erosion in the rainy season.

[4] One of the TMCF regions that has been a subject of extensive research is the Monteverde cloud forest in Costa Rica [Wheelwright, 2000]. The Monteverde cloud forests, which host a very diverse flora and fauna, sits on the crest of Cordillera de Tilarán, which rises sharply from the lowlands of northwestern Costa Rica. The Cordillera is located at about $125 \mathrm{~km}$ from the Caribbean coast. The forest preserve extends from the crest of the Cordillera at $1500-1800 \mathrm{~m}$ down to $700 \mathrm{~m}$ on the Caribbean slope and to $1300-1500 \mathrm{~m}$ on the Pacific slope. The lower Pacific slope is now mostly deforested. As in other cloud forests, horizontal precipitation accounts for a significant amount of the total precipitation in the Monteverde region. On average horizontal precipitation contributes about $45 \%$ of the total annual precipitation along the continental divide [Haeger and Dohrenbusch, 2004] and about $22 \%$ in a leeward cloud forest at the same elevation $1.5 \mathrm{~km}$ away [Clark et al., 2000], but this number is significantly higher during the dry season, which extends from February through April. During the dry season, input of moisture from the horizontal precipitation process is critical, since the ecosystem is then under greater physiological water stress than in the wet season.

[5] Pounds et al. [1999] report an increase in the dry season (February-April) mist free days in the Monteverde preserve region since the early 1970s. Anuran population crashes and bird migrations to higher elevations during the same time period have been attributed to the reduction in the crucial moisture input from dry season mist. It has been suggested that the longer dry season mist free periods at the lee edge of Monteverde TMCF is due to an increase in the base height of the orographic cloud bank, resulting from changes in sea surface temperature [Pounds et al., 1999]. Still et al. [1999] argue that increased sea surface temperature leads to intensification of tropical hydrological cycle in a manner analogous to that observed in global climate model (GCM) simulations of doubled atmospheric carbon dioxide $\left(2 \mathrm{XCO}_{2}\right)$. The enhanced latent heat release from intensification of the hydrological cycle and subsequent warming of the atmosphere might lead to the rise in the lifting condensation level, and with it the height of orographic cloud banks [Still et al., 1999; Pounds et al., 1999]. However, GCM studies with coarse grid spacing are unable to resolve small-scale terrain features and land use information. Still et al. [1999] suggest using mesoscale regional models that better resolve the topography and local land use changes to further explore the impact of climate change on TMCFs.

[6] The trade winds from the Caribbean traverse a distance of approximately $125 \mathrm{~km}$ over the Costa Rican lowlands before the slopes of Cordillera de Tilarán lift the air, resulting in the formation of orographic cloud banks. Through heat and moisture exchange, the land surface has the potential to substantially modify the boundary layer air in which the orographic clouds ultimately form, upon being lifted by the slopes of Cordillera de Tilarán. Originally tropical moist and wet forests covered most of the Costa Rican lowlands. However, by 1992, deforestation had reduced the forest cover in the Costa Rican lowlands to about $1200 \mathrm{~km}^{2}$ (18\% of the area of the original forest cover) [Veldkamp et al., 1992].

[7] Lawton et al. [2001] and Nair et al. [2003] used satellite data to show that cumulus cloud formation is suppressed over deforested areas in the Costa Rican lowlands. Using numerical modeling experiments, they also showed that conversion of surface vegetation from forest to pasture resulted in substantial differences in lowland cumulus cloud formation. In addition to differences in cloud field organization, the average cloud base height, cloud thickness, cloud top height, cloud liquid water content and cloud water path all differed when the surface vegetation was changed from forest to pasture. The average cloud base height increased substantially (maximum difference of $\sim 750 \mathrm{~m}$ ) when the surface characteristics for the entire model domain were changed from that consistent with forest to that of a pasture. Lawton et al. [2001] and Nair et al. [2003] concluded that land use changes in the Caribbean lowlands could alter the nature of the air masses responsible for the formation of cumulus clouds, and suggested that the formation of orographic cloud could be affected by deforestation in the Caribbean lowlands.

[8] This paper extends the preliminary work of Lawton et al. [2001] and Nair et al. [2003] and explores in detail the impact of lowland deforestation on orographic cloud formation along the Caribbean slopes of Cordillera de Tilarán. The main objective for the present study is to investigate the effects of deforestation in the Costa Rican lowland and premontane regions on orographic cloud formation along the Caribbean slopes of Cordillera de Tilarán during the dry season month of March using the CSU RAMS mesoscale numerical model. High-spatial resolution CSU RAMS simulations, constrained by a variety of ground based and remotely sensed observations, are used to examine the sensitivity of orographic cloud formation in the Monteverde region to three different land use scenarios in the adjacent lowland and premontane regions. The land use scenarios considered in the present study are more realistic compared to the simple forest and pasture scenarios considered in the preliminary analysis of Lawton et al. [2001] and Nair et al. [2003].

[9] A brief description of the study area is given in section 2. The data used in this study are described in section 3, while section 4 discusses the methodology. 


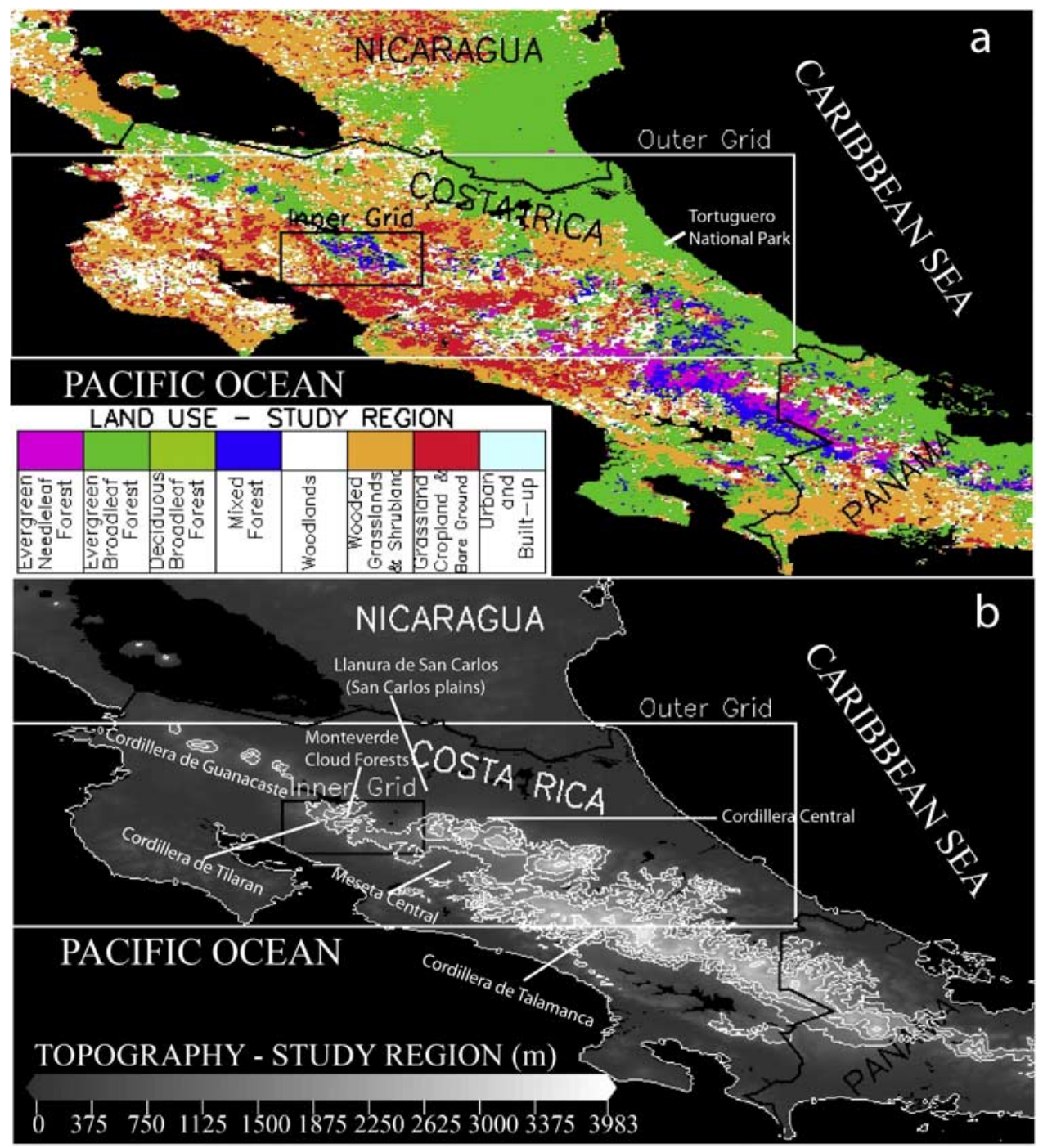

Figure 1. (a) Current land use in the study region derived from the UMD MODIS ecosystem database. Note the location of the outer grid that stretches out to the Caribbean Sea in the east and the Pacific Ocean in the west. The inner grid is centered on the Monteverde region. Extensive areas of the Pacific lowland as well as some of the Atlantic lowlands are deforested. (b) Mountain tops covered with forests. Note that the evergreen needleleaf forests and mixed forests shown in Figure 1a is a misclassification. These are actually evergreen broadleaf forests and are treated as such in the RAMS model.

Section 5 presents analysis of the RAMS simulations, and section 6 concludes.

\section{Study Area}

[10] The area of interest in this study is centered on the Monteverde region in the northern part of Costa Rica. The Monteverde cloud forest is situated at the crest of Cordillera de Tilarán (Figure 1a), where the mountain range rises to elevations in excess of $1800 \mathrm{~m}$ (Figure 1b). The volcanic Cordillera Central extends to the southeast with peaks ranging from 2100 to $3400 \mathrm{~m}$. To the northwest lie isolated volcanoes $(1400-1800 \mathrm{~m})$ of the Cordillera de Guanacaste. The flow of trade winds over these mountains results in the formation of orographic cloud banks along the windward Caribbean slopes. Immersion of forests in clouds along these slopes is responsible for one of the richest cloud forest ecosystems in the world.

[11] Forest cover in the Costa Rican region has declined considerably during the past century. Sader and Joyce [1988] estimated that the primary forest cover in Costa Rica decreased from $67 \%$ of the land area in 1940 to $17 \%$ in 1983. A more recent study by Carlson and SanchezAzofeifa [1999] reported 29\% forest cover for 1991 with an average annual deforestation rate of $4.2 \%$ of the remaining forest per year. These censuses pertain to the country as a whole, but most remaining forest is on the mountains. The lowland and premontane regions are largely deforested except in a few National Parks and Wildlife Refuges.

[12] The majority of the Costa Rican lowland and premontane regions in the study area, the San Carlos and Tortuguero plains to the east of the Monteverde, have a 
long history of deforestation with the exception of Tortuguero National Park and adjacent swamps located south of the Costa Rica-Nicaragua border [Reiners et al., 2002, Figure 1]. However, across the border in Nicaragua, the forest cover remains relatively intact [Lawton et al., 2001].

\section{Data}

[13] The present study utilizes rawinsonde, in situ soil moisture observations, remotely sensed clouds, land use and vegetation characteristics, output from global-scale numerical models and other physiographical data sets for both initializing and validating the RAMS simulations. Initial atmospheric conditions and lateral boundary conditions for the RAMS simulations were analyzed from rawinsonde data obtained during the LUCIE field experiment and from the NCEP reanalysis data [Kalnay et al., 1996]. The LUCIE field experiment was carried out in March 2003 over Costa Rica, with the two objectives of (1) characterizing the development of the boundary layer over paired forested and deforested sites and (2) measuring the atmospheric thermodynamic structure over the Caribbean plains.

[14] Prior modeling studies of Lawton et al. [2001] and Nair et al. [2003] utilized radiosonde observation from San Andres island (in the Caribbean to the east, and upwind of Costa Rica) since the only radiosonde observations available from Costa Rica are from San José on the Meseta Central, which is certainly not representative of conditions over the Caribbean plain. During the LUCIE field campaign coincident rawinsonde launches were conducted over several paired forested and deforested sites at 3-hour intervals starting from 0600 Local Time (LT) to 1800 LT on most of the days of March. The paired sites were chosen to sample atmospheric conditions over forested and deforested sites at varied distances from the Caribbean coast.

[15] The National Center for Atmospheric Research (NCAR) Global Positioning System (GPS)/Loran Atmospheric Sounding System used during the LUCIE field campaign reported temperature, humidity and wind measurements at every $5 \mathrm{hPa}$ interval. These high-vertical resolution observations were subsampled for the purpose of initializing RAMS and also for specifying the temporally varying lateral boundaries. The significant levels were retained by imposing the condition that the difference in temperature, and wind speed between any two subsampled sounding levels is greater than $1 \mathrm{~K}$, and $1 \mathrm{~ms}^{-1}$ respectively. The significant levels for pressure, geopotential height, and relative humidity corresponded to those of the temperature significant levels, whereas those for wind direction corresponded to that of wind speed. These thresholds were derived by trial and error to minimize the difference between the sub sampled and complete rawinsonde observation in the boundary layer, since the boundary layer thermodynamics has the most significant impact on orographic cloud formation.

[16] The United State Geological Survey (USGS) $1 \mathrm{~km}$ resolution topography data were used to specify terrain in RAMS simulations. Global land use categorization at $1 \mathrm{~km}$ spatial resolution developed by the University of Maryland (UMD) [Hansen et al., 2000] using Moderate Resolution Imaging Spectroradiometer (MODIS) imagery is used to specify the type of vegetation in RAMS simulations. Leaf
Area Index (LAI), a crucial input characteristic for the vegetation parameterization within RAMS, is also specified using MODIS derived LAI at $1 \mathrm{~km}$ spatial resolution [Myneni et al., 1997; Knyazikhin et al., 1998] available at 8-day intervals. The LAI values used in this study are based on MODIS imagery acquired over the study area during the time period 6-13 March 2003. A Food and Agricultural Organization (FAO) based $1^{\circ} \times 1^{\circ}$ resolution soils database is utilized for specifying the soil type in the study area. While silt-clay is the dominant type of soil in the study area some sandy-clay-loam is also present.

[17] The GOES 8 imagery is used to validate the RAMS simulation of orographic cloud banks. An automated cloud classification algorithm [Nair et al., 1999] utilizes a time series of $1 \mathrm{~km}$ spatial resolution visible channel imagery to detect clouds in the study area for comparison to RAMS simulated cloud fields.

[18] GOES 8 imagery has five spectral channels, with one in the visible $(0.52-0.72 \mu \mathrm{m})$ and four in the infrared region $(3.78-4.03 \mu \mathrm{m}, 6.47-7.02 \mu \mathrm{m}, 10.2-11.2 \mu \mathrm{m}$, $11.5-12.5 \mu \mathrm{m})$. Spatial resolution at nadir for channel 1 is $1 \mathrm{~km}, 4 \mathrm{~km}$ for channels 2,4 , and 5 , and channel 3 has nadir resolution of $8 \mathrm{~km}$. Only the visible channel is used in the present study.

\section{Methodology}

[19] The main hypothesis explored in this study is that deforestation in the lowland and premontane regions, upwind of the Cordillera de Tilarán, leads to the formation of warmer and drier air masses, resulting in orographic cloud banks forming at higher elevations and with smaller spatial extent during the dry season. As in the sensitivity study reported in the companion papers, [Lawton et al., 2001; Nair et al., 2003], a coupled design is used to investigate the effect of varied surface conditions on orographic cloud formation. Orographic cloud formation in the study area, during the time period of 1-14 March of 2003, is simulated using CSU RAMS for the three scenarios: (1) pristine conditions, i.e., completely forested, including the lowland and premontane regions; (2) current conditions, i.e., MODIS ecosystem classification; and (3) future scenarios with only deforestation in the lowland and premontane regions; mountain tops remain forested (Figure 2). The MODIS derived land use map [Hansen et al., 2000] misclassifies some of the evergreen broadleaf vegetation in the cloud forests as evergreen needleleaf and mixed forests. The occurrence of these ecosystem types in the study area are therefore replaced by evergreen broadleaf forests.

[20] The CSU RAMS [Pielke et al., 1992], a nonhydrostatic numerical modeling system, is used for simulating a wide range of atmospheric phenomenon and utilizes finite difference approximations to solve conservation equations of mass, momentum, heat, and solid and liquid phases of water. The finite difference equations are solved within a grid structure that uses a polar stereographic projection in the horizontal, and a terrain following sigma coordinate system in the vertical [Mahrer and Pielke, 1975]. An explicit, detailed cloud microphysical parameterization accounts for the various cloud processes [Walko et al., 2000], while a multilayer soil model [Tremback and Kessler, 1985] and a vegetation model [Walko et al., 2000] repre- 

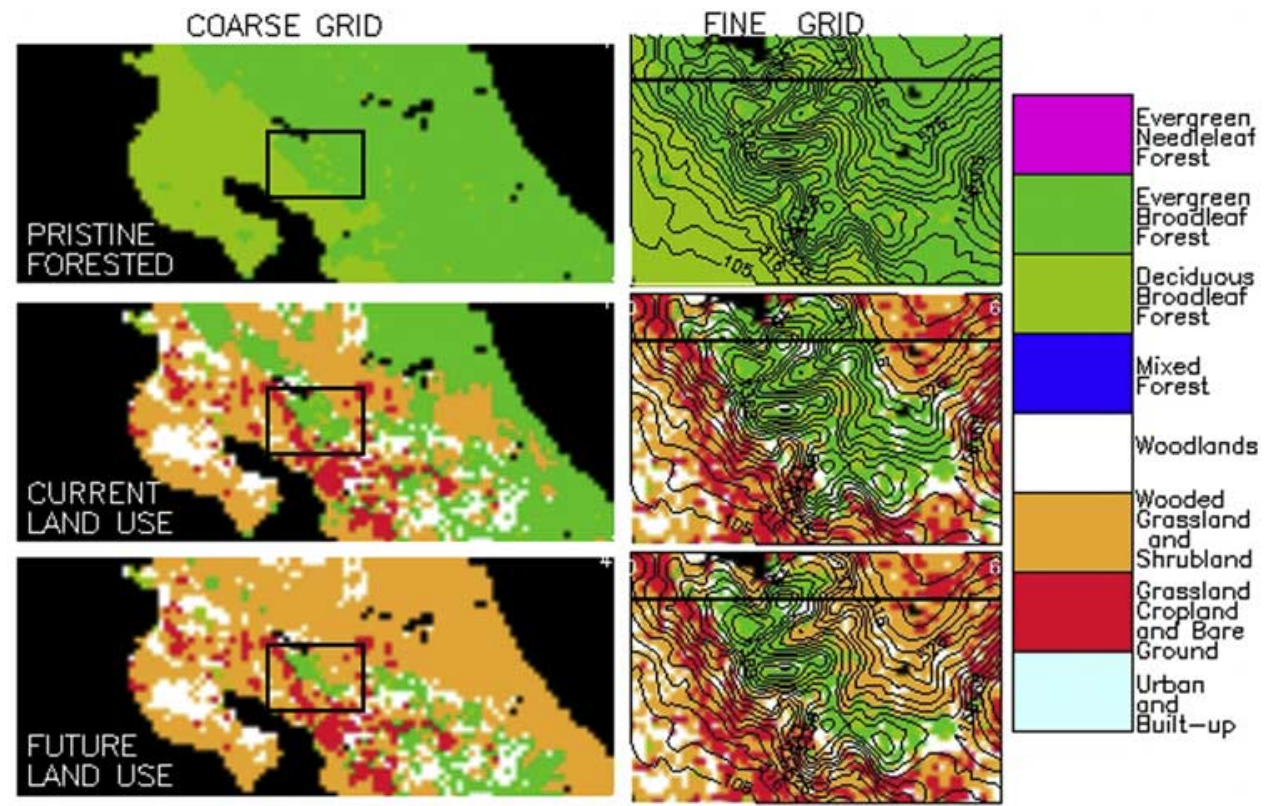

Figure 2. Land use prescribed for the three models for the outer and inner nested (fine) grid. The topography is plotted over the land use for the inner nested grid to show the locations in the mountain tops that are expected to continue to have forest cover also in the deforested/future scenario. Also plotted are the horizontal lines in the nested (fine) grid showing the locations for cross section plots (see Figure 5). In the deforested/future scenario all the forests found below $1000 \mathrm{~m}$ on the Atlantic side were deforested, as were areas below $1400 \mathrm{~m}$ on the Pacific side.

sents the various land surface processes. The RAMS provides a wide range of ways for representing atmospheric radiative transfer, subgrid-scale turbulence, top and lateral boundary conditions.

[21] The simulations used a nested grid configuration (Figures 1 and 2), consisting of a coarse outer grid of $4 \mathrm{~km}$ grid spacing and domain of $400 \times 160 \mathrm{~km}$ with a finer nested grid of $1 \mathrm{~km}$ spacing and domain covering $62 \times 42 \mathrm{~km}$ area, both centered approximately on the Monteverde region $\left(10.25^{\circ} \mathrm{N}, 84.7^{\circ} \mathrm{W}\right)$. In the vertical a stretched grid was used, with a grid stretch ratio of 1.2 and grid spacing that varied from $20 \mathrm{~m}$ near the surface to $750 \mathrm{~m}$ higher up in the atmosphere. The mean heights of the first 10 levels are $9.5 \mathrm{~m}, 31.5 \mathrm{~m}, 57.7 \mathrm{~m}, 89.3 \mathrm{~m}, 127.2 \mathrm{~m}, 172.6 \mathrm{~m}, 227.1 \mathrm{~m}$, $292.5 \mathrm{~m}, 371.0 \mathrm{~m}$, and $465.2 \mathrm{~m}$, above the ground, respectively. Land use categories and topography within these grids are shown in Figures 1 and 2. Note that the coarse grid is approximately centered on the western edge of the Costa Rican lowlands and extends into the Caribbean, covering the lowland and premontane areas to the east of Monteverde and also a considerable fetch of the ocean both to the east and to the west, insulating the finer grid from lateral boundaries effects and at the same time providing inputs of larger-scale atmospheric flow into the fine grid.

[22] The initial atmospheric conditions and temporally varying lateral boundary forcing for RAMS is provided by the rawinsonde profiles obtained during the LUCIE field campaign and by NCEP reanalysis data. The nudging option is used along the lateral boundaries, where the time series of atmospheric dynamic and thermodynamic field analysis is used to relax the atmospheric conditions along the lateral boundaries toward observations. This is achieved by nudging the current value of a variable at a grid point along the lateral boundaries by an amount proportional to difference between the current and future values where the future value is prescribed by the LUCIE-NCEP analysis fields. Five points along the lateral boundaries were nudged with nudging strength exponentially decreasing toward the domain interior. A nudging timescale of $900 \mathrm{~s}$ was used. The Klemp and Wilhelmson [1978] lateral boundary conditions were applied to the coarse grid, in which the normal velocity component specified at the lateral boundary is effectively advected from the interior assuming a propagation speed. This boundary condition allows disturbances to propagate out of the model domain without strongly reflecting back into the interior.

[23] The explicit microphysical parameterization [Walko et al., 2000] option within RAMS is used in simulation of the orographic cloud banks. The atmospheric radiative transfer scheme of Harrington and Olsson [2001] that accounts for the effects of clouds and water species in the atmosphere is utilized in this study. In the horizontal a deformation based scheme is used to represent diffusion, while in the vertical, diffusion is parameterized using the Mellor and Yamada [1982] scheme.

[24] The soil depth for the study area, reported in the FAO soil database [Webb et al., 1992; Food and Agriculture Organization, 1971; Gerakis and Baer, 1999], varies from $2.0 \mathrm{~m}$ to $3.0 \mathrm{~m}$. Since the soil model within RAMS allows only for a homogenous soil depth, an average value of $2.5 \mathrm{~m}$ was chosen as the depth of the soil layer. In situ observations collected from the study area during March of 2003 are used to initialize the soil moisture profile in RAMS. Field observations of soil moisture in the forested and deforested areas in 
the lowland and premontane regions do not show significant differences up to a depth of $1 \mathrm{~m}$. The soil saturation, as percent of field capacity in these areas, varies between $10-15 \%, 10-$ $20 \%$ and $25-30 \%$ at 20,50 and $100 \mathrm{~cm}$ soil depth, respectively, both over forested and deforested areas. However, field observations suggest pasture grasses in deforested areas are more stressed during the dry season than are trees, as might be the case if trees have access to water stored in deeper soil layers. Prior studies in eastern Amazonia suggests that $75 \%$ of all the water extracted during the dry season originates from soil layers below the depth of $2 \mathrm{~m}$ [Nepstad et al., 1994].

[25] Consistent with field observations from the study region, the initial soil saturation prescribed in the simulations varied from 0.1 at the surface, 0.2 at $50 \mathrm{~cm}$ depth, to 0.3 at $1.0 \mathrm{~m}$ soil depth. In order to account for access to soil water from deep soil layers by the forest, the soil saturation was linearly increased from 0.3 at $1 \mathrm{~m}$ depth to 0.8 at $2.5 \mathrm{~m}$ soil depth. Adequate representation of deep soil water access by forests within RAMS requires characterization of root profiles within the forest, and also observation of soil moisture at depths greater than $1 \mathrm{~m}$. Since such data are not available at present, forest vegetation in RAMS, which has a rooting depth of $2 \mathrm{~m}$, is provided sufficient access to soil water by increasing the soil saturation from 0.3 at $1 \mathrm{~m}$ depth to 0.8 at $2.5 \mathrm{~m}$ depth. The prescribed soil moisture profile thus assumes that the forest vegetation has access to deep soil layers and is less water stressed compared to deforested areas, consistent with the field observations.

[26] The spatial distribution of vegetation types for the pristine, current and deforested land use scenarios were defined as follows. In the pristine scenario evergreen broadleaf vegetation covers the areas from the crest of the Cordilleras to the Caribbean coast and deciduous broadleaf vegetation covers from the Pacific slopes $(<750 \mathrm{~m})$ to the coast (Figure 2). This is broadly consistent with the tropical wet and moist forests originally present [Gomez, 1986] and associated with Holdridge [Holdridge, 1967] life zones. The current land use scenario is prescribed using the UMD $1 \mathrm{~km}$ spatial resolution land use type classification [Hansen et al., 2000] (Figures 1a and 2), one of the most up-to-date land use databases available. The deforested land use scenario assumes that the deforestation proceeds up to $1000 \mathrm{~m}$ and $1400 \mathrm{~m}$ on the Caribbean and Pacific slopes of the Cordillera (Figure 2) respectively. These are values based on observed patterns of land use in the area and reflect the relative ease of clearing land on the drier Pacific slope.

[27] The LEAF-2 vegetation model assigns fixed characteristics such as albedo, roughness length, and LAI, depending upon the land use type that varies as a function of season in the model. For the current land use scenario, the spatial distribution of LAI is specified using the more representative MODIS derived LAI data set. In the pristine land use scenario, the average LAI values found over the remnant evergreen broadleaf (5.1) and deciduous broadleaf forests (3.0) at present are assigned for the forests that replace areas that are currently deforested. The areas that are currently forested retain the current MODIS derived LAI values in the pristine land use scenario. In the deforested scenario, areas below $1000 \mathrm{~m}$ and $1400 \mathrm{~m}$ on the Atlantic and Pacific side respectively that are currently covered by forests are converted to wooded grasslands, with LAI values of 2.0 and 1.2 on the Atlantic and Pacific sides, respectively. These values are consistent with the average MODIS derived LAI values observed for the current wooded grasslands on the Atlantic and Pacific sides.

[28] The RAMS, initialized using 1 March 2003, 1200 UTC (0600 LT) observations, was integrated for a time period of 14 days for the three land use scenarios. The simulations used a time step of $4 \mathrm{~s}$ for the coarse grid and $1 \mathrm{~s}$ for the inner fine grid. The tendencies from the radiative transfer calculations are updated once every $300 \mathrm{~s}$. The analysis fields derived from NCEP reanalysis and LUCIE rawinsonde observations, available every 6 hours, were used to nudge the lateral boundaries.

\section{Results}

[29] The two week period model simulations for the three land use scenarios are analyzed with the following objectives: (1) to assess the ability of the modeling system to simulate the orographic cloud formation for the present land use distribution, (2) to assess the differences in the orographic cloud areal cover between the three land use scenarios, (3) to examine the differences in orographic cloud bases between the three land use scenarios, and (4) to characterize the differences in the nature of the lowland and premontane air masses that are responsible for the differences in observed orographic cloudiness.

\subsection{Comparison Between Model-Simulated and Satellite Observed Clouds and Rawinsonde Profiles}

[30] The model-simulated orographic cloudiness is compared to GOES 8 observed cloudiness at various times of the day to assess the performance of the model. The RAMS simulated clouds within the $1 \mathrm{~km}$ spaced fine grid are compared on a point-by-point basis against $1 \mathrm{~km}$ spatial resolution GOES 8 observed clouds, with the objective of quantifying the performance of the model. An automated cloud detection algorithm [Nair et al., 1999] was applied to GOES 8 imagery acquired at 1215, 1315, 1415, 1515, 1615, $1815,1915,2015,2115$ and 2215 UTC. The cloud mask generated by the automated cloud detection algorithm was used for comparison and an accuracy measure (X) was computed to evaluate the RAMS simulation. The accuracy measure $\mathrm{X}$ is computed using the following expression:

$$
\mathrm{X}=\mathrm{x} 1 /(\mathrm{x} 1+\mathrm{x} 2+\mathrm{x} 3)
$$

where $\mathrm{x} 1, \mathrm{x} 2$, and $\mathrm{x} 3$ are the number of grid points in which the comparison shows occurrence of clouds in both the model and satellite imagery (x1), in the model but not the satellite imagery (x2), and in the satellite imagery but not the model (x3), respectively.

[31] In general the spatial distribution of model-simulated clouds show remarkable similarities to satellite observed clouds (Figure 3a). The daytime variation of the model accuracy $(\mathrm{X})$, for the time period of 1-14 March is shown in Figure 3b; however, a total of 142 comparisons shows a wide range of accuracies, from 0.0 to nearly $87.0 \%$. The lowest accuracy values are generally for those times when GOES observations either showed weak cloud development which the model failed to simulate, or when orographic clouds were poorly developed and simulated at locations 

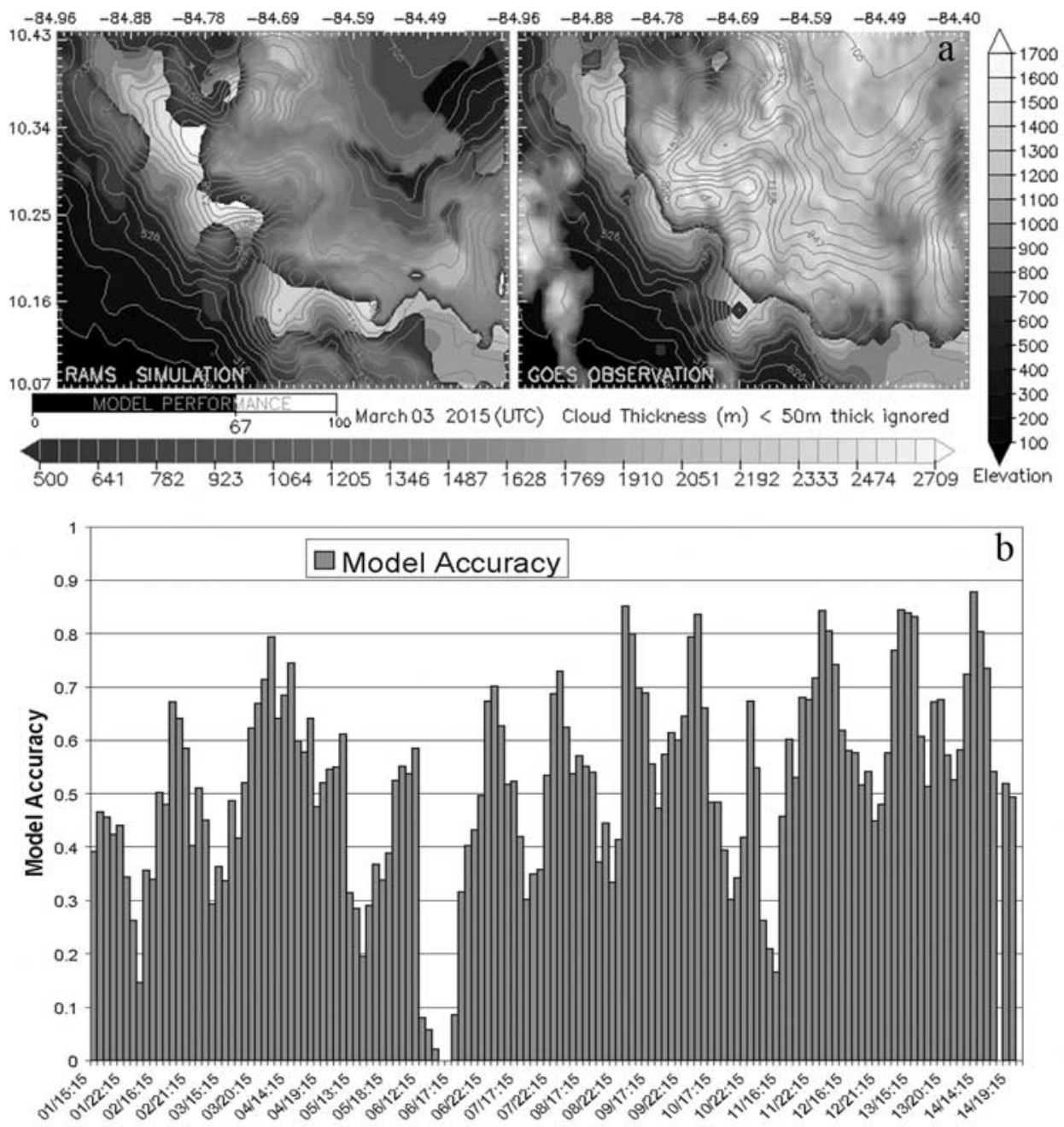

Validation date and time

Figure 3. (a) An example of model performance from 3 March 2003 at 1415 LT (2015 UTC). The left plot shows the clouds simulated using RAMS. The right plot is the corresponding GOES satellite observation. The GOES observation plotted are the actual brightness values. Brighter clouds are expected to be optically thicker that in turn could be geometrically thicker. Using this information the RAMS simulated clouds are plotted on a color scale that makes thicker simulated clouds to be brighter. This provides us with an opportunity to qualitatively see whether the simulated clouds have similar thickness as it appears in the GOES clouds. However, the actual model versus simulation comparison is based on whether a cloud was simulated in the same place where there was a GOES observed cloud. Where clouds are not present, the topography is visible. In general, the mountain tops are covered with clouds, and clouds seem to be extending from the Atlantic lowlands to the mountains. The model accuracy in this case was $67 \%$. (b) Model performance for all the days from 1 to 14 March for each time when GOES imagery was available for comparison plotted as histograms. A value of 0 means that there was no overlap in the area of cloud simulated and observed, whereas a value of 1 would be that for each point the model-simulated cloud, there was a GOES observed cloud. Additionally, it would also mean that there was no cloud simulated that was not observed and there was no cloud observed that was not simulated.

different from those at which clouds were observed. In general the model performance varies from 0.2 to 0.7 and is often within the range of 0.4 to 0.6 . An analysis of the spatial pattern of simulated and observed clouds shows that when model performance $(\mathrm{X})$ is greater than 0.4 , the simulated and observed cloud fields actually match well. In these cases, the error is largely due to differences in cloud positions in simulated and observed cumulus cloud fields upwind of the mountains, and in the positions of observed and simulated small lee wave clouds on the Pacific slope. Consequently, an accuracy of 0.4 is used as the criteria for satisfactory/good model performance. Out of a total of 142 comparisons of model performance conducted, 102 cases $(\sim 72 \%)$ had accuracies of $40 \%$ or higher. Six days, 2, 3, 4, 9, 12, and 13 March, exhibited the best model performance $(87.5 \%$ of the cases had accuracies greater than $40 \%$ with $70.3 \%$ having greater than $50 \%$ accuracy). 

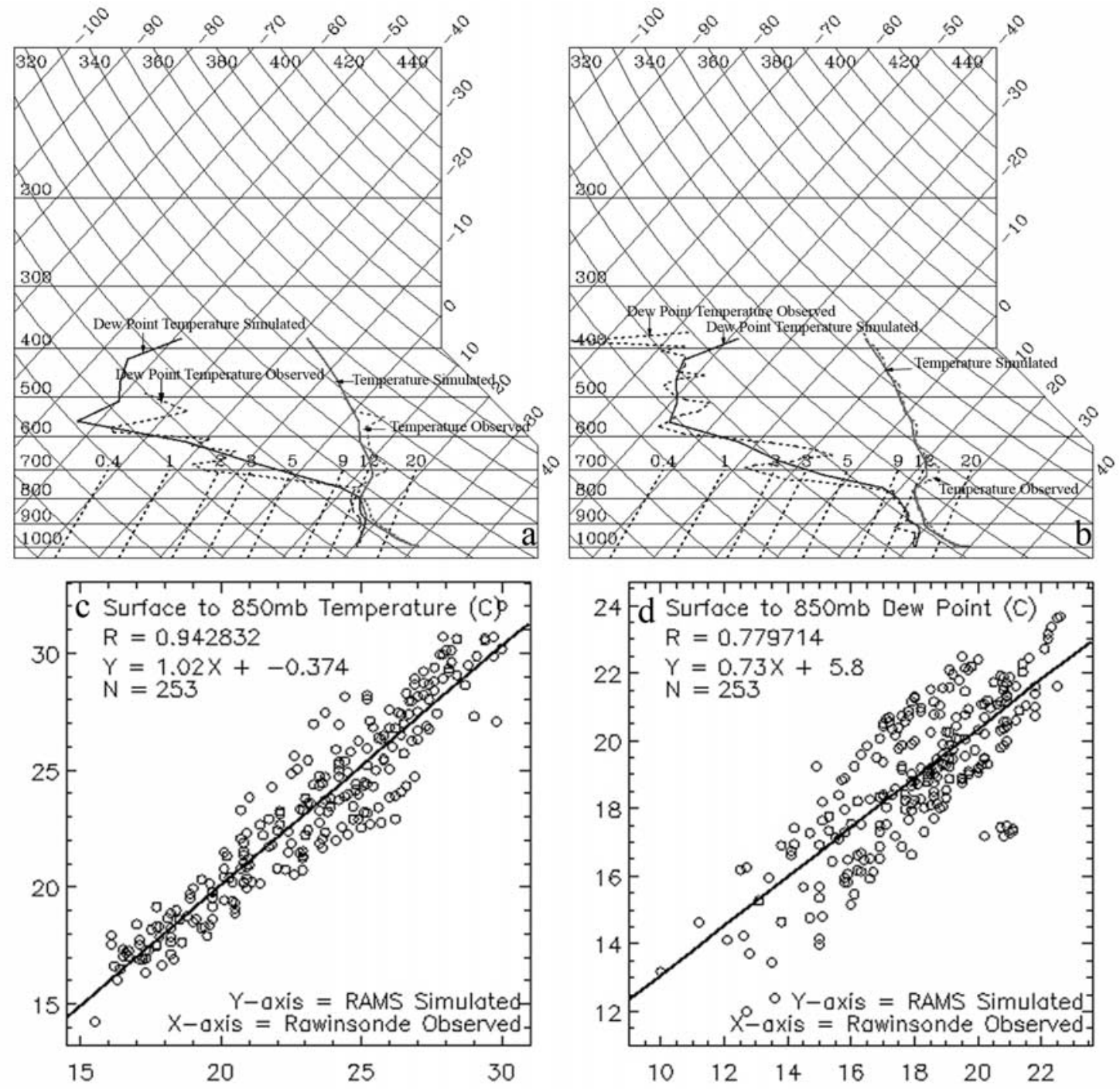

Figure 4. Examples of RAMS simulated (solid line) and rawinsonde observed (dashed line) temperature and dew point temperature from 4 March at around 1500 LT (2100 UTC). (a) Located at $10.5^{\circ} \mathrm{N}, 84.5^{\circ} \mathrm{W}$ and was launched at $1452 \mathrm{LT}$ and compared with RAMS profile at this location from 1445 LT. (b) Located at $10.45^{\circ} \mathrm{N} 83.7^{\circ} \mathrm{W}$ and was launched at $1455 \mathrm{LT}$ and compared with RAMS profile at this location from 1500 LT. Thus there is some time lag between the rawinsonde observed and the RAMS comparison. Generally, they compared very well in the lower atmosphere, which is of maximum importance to this study. (c) Scatterplot of rawinsonde observed versus RAMS simulated temperature from the surface to $850 \mathrm{mb}$ taking the days of 2, 3, 4, 12 and 13 March at three times of the day (0900, 1200, and 1500 LT approximately). (d) Same as Figure 4c but for dew point temperature.

[32] For the 6 days that the model simulated orographic clouds at Monteverde the best, we further investigated if the simulated atmospheric profiles of air temperature and dew point air temperature compared favorably with observed rawinsonde profiles at approximately three times of the day: 0915, 1215 and 1515 LT. In general the simulated temperature profiles matched the observed temperature profiles better than (Figures $4 \mathrm{a}$ and $4 \mathrm{~b}$ ) dew point air temperature profiles. The maximum deviations between the simulated and observed temperature took place between $850 \mathrm{mb}$ and $700 \mathrm{mb}$ (Table 1), whereas at other levels they were well matched. For the current study, the surface to $850 \mathrm{mb}$ atmospheric level however, is the most important since we are investigating orographic cloud base heights under the three different lowland and premontane land use scenarios. In the surface to $850 \mathrm{mb}$ atmospheric layer the correlations between the simulated and observed temperature is 0.94 (Figure 4c). Often the lifting condensation levels (LCL) were also within the surface to $850 \mathrm{mb}$ layer. Figure $4 \mathrm{~b}$ shown one such example when the LCL was at around $900 \mathrm{mb}$. While the simulated dew point temperature profiles in general matched the observed dew point temperature profiles there were often large deviations between the two (often around $5-10^{\circ} \mathrm{C}$ ) and especially above $700 \mathrm{mb}$ (Figures $4 \mathrm{a}$ and $4 \mathrm{~b}$ ). However, for this study the lower atmosphere (surface to $850 \mathrm{mb}$ ) is the 
Table 1. Correlations Between Rawinsonde Observed and RAMS Simulated Temperature and Dew Point Temperature Profiles at Different Atmospheric Layers ${ }^{\mathrm{a}}$

\begin{tabular}{lccl}
\hline Atmospheric Level & Temperature & $\begin{array}{c}\text { Dew Point } \\
\text { Temperature }\end{array}$ & $\mathrm{N}$ \\
\hline Surface to $850 \mathrm{mb}$ & 0.94 & 0.78 & 253 \\
$850 \mathrm{mb}$ to $700 \mathrm{mb}$ & 0.56 & 0.83 & 89 \\
$700 \mathrm{mb}$ to $550 \mathrm{mb}$ & 0.95 & 0.89 & 92 \\
Above $550 \mathrm{mb}$ & 1.00 & 0.85 & 128 \\
\hline
\end{tabular}

${ }^{\mathrm{a}}$ Each point used in the computation was at observed-simulated pressure level $<0.1 \mathrm{mb}$. Days used in the analysis were 2, 3, 4, 12, and 13 March and for the three times of roughly, 0900, 1200, and 1500 LT. Rawinsondes were not launched on 9 March.

most important and here the profiles generally matched well (Figure $4 \mathrm{~d} ; \mathrm{r}=0.78$ ). One of the reasons the RAMS simulated profiles matched less well with the observations above $700 \mathrm{mb}$ is because the RAMS profiles are over static locations while the rawinsondes when launched, drifted in space, especially at higher atmospheric levels. Therefore it is likely that comparisons are valid only at lower elevations. Since we are especially interested in cloud base heights the good match between the simulated and observed profiles suggests that orographic clouds were well simulated on these 6 days.

\subsection{Effect of Lowland and Premontane Deforestation on the Clouds Over Cloud Forests}

[33] Preliminary studies by Lawton et al. [2001] and Nair et al. [2003] suggest that lowland and premontane deforestation leads to increases in cloud base heights not only over the lowland and premontane regions but also in the highlands downwind of the deforested sites. In order to explore this hypothesis, the diurnal variations of domain averaged cloud base heights, both over lowland and premontane regions and highlands, and the spatial variations of cloud base heights are examined. In addition, diurnal variations of the lowland and premontane energy fluxes, air temperatures and dew point temperatures are also investigated for the three land use scenarios.

5.2.1. Terrain Intersection by Orographic Cloud Banks

[34] Numerical simulations show that the daytime orographic cloud banks in the three land use scenarios intersect the mountains at different locations. The east-west cross sections (Figure 2) of the numerically simulated orographic cloud banks in the Monteverde (Figure 5) region for 1430 LT generally show orographic cloud banks forming at lower elevations on the Caribbean and Pacific slopes for the pristine land use scenario as compared to the current and deforested land use scenarios. The orographic cloud bank sometimes forms on the mountain tops in the completely forested scenario when it does not intersect the terrain at all in the current and deforested scenarios. For example, the forested scenario for 2 March shows orographic cloud forming on the top of the eastern peak and extending down to altitudes of 1300 and $1400 \mathrm{~m}$ on the eastern and western slopes, respectively (Figure 5a), while the cloud bank does not intersect the eastern peak in the other scenarios (Figures $5 \mathrm{~b}$ and $5 \mathrm{c}$ ). The orographic cloud bank in the completely forested scenario on other days (Figures 5d, 5g, 5j, 5m, and $5 \mathrm{p}$ ) also extends to lower elevations on the Caribbean slopes compared to the current (Figures 5e, 5h, 5k, 5n, and 5q) and deforested scenarios (Figures 5f, 5i, 51, 5o, and 5r). The differences in lower extent of orographic cloud bank on the Caribbean slope between the completely forested and current scenarios and the completely forested and deforested scenarios range between 0-200 $\mathrm{m}$ and 50-300 m, respectively. Simulations for 4, 12 and 13 March show the orographic cloud cover in the saddle/ valley region between the eastern and western slopes reaching the base of the valley for the completely forested scenario (Figures $5 \mathrm{~g}, 5 \mathrm{~m}$, and 5p), while in the current (Figures 5h, 5m, and $5 q$ ) and deforested (Figures 5i, 5n, and 5r) scenarios the valley base tends to be cloud free. Lowland and premontane deforestation also impacts the manner in which orographic cloud banks spill over onto the lee Pacific slopes. Orographic cloud banks in the completely forested scenario extend further down the Pacific slope on 4, 9, 12 and 13 March (Figures 5g, 5j, 5m, and 5p) compared to the current (Figures $5 \mathrm{~h}, 5 \mathrm{k}, 5 \mathrm{n}$, and $5 \mathrm{q}$ ) and the deforested (Figures 5i, 51, 5o, and 5r) scenarios. The range of differences in the lower extent of Pacific slope orographic cloud banks between the completely forested and current and the completely forested and deforested scenarios are $0-75 \mathrm{~m}$ and $100-175 \mathrm{~m}$, respectively. The location of the cloud bank on the lee slope is important for cloud forests such as the Monteverde Cloud Forest Preserve, which are situated close to boundaries between misty and clear regions.

\subsubsection{Spatial Pattern of Average Cloud Base Heights}

[35] Average cloud base heights were taken at 1430 LT for the six cases described above. Then differences were taken between the completely forested and current and the deforested/future and current scenarios. Figure $6 \mathrm{a}$ shows a pattern in which cloud base height generally is lower in the completely forested scenario compared to the current and the deforested scenarios. Cloud base height at each grid point is determined as the height of the first model vertical level above the surface with nonzero liquid water content. The average difference in cloud base heights between the different scenarios is greater over lowland and premontane regions than it is over the highlands. At 1430 LT, the difference in averaged cloud base height between the forested and current land use scenario ranges between 200-400 $\mathrm{m}$ in the lowlands (Figure 6a), while the deforested/future land use scenario leads to an additional difference of $200 \mathrm{~m}$. However, the changes in cloud base heights over the currently forested highlands are more critical for the cloud forests. Figure 6 a shows that cloud base heights have risen by $50-100 \mathrm{~m}$ in response to deforestation from the completely forested to the current state. Total deforestation of the lowlands is projected to lead to additional increases in cloud base heights ranging from $50 \mathrm{~m}$ to $100 \mathrm{~m}$ (Figure 6b). Clearly, the deforestation in the lowland and premontane regions and cloud formation over the montane regions are coupled.

\subsubsection{Diurnal Variation of the Highland Forest Areas Experiencing Cloud Immersion}

[36] Immersion in cloud is one of the defining characteristics of a cloud forest ecosystem, and thus changes in areal extent of elevated regions subject to cloud immersion is of crucial importance. Numerical model simulations are utilized to examine the diurnal variation in the areal extent of highland regions immersed in clouds in the three land use scenarios. The highland regions considered are those ele- 


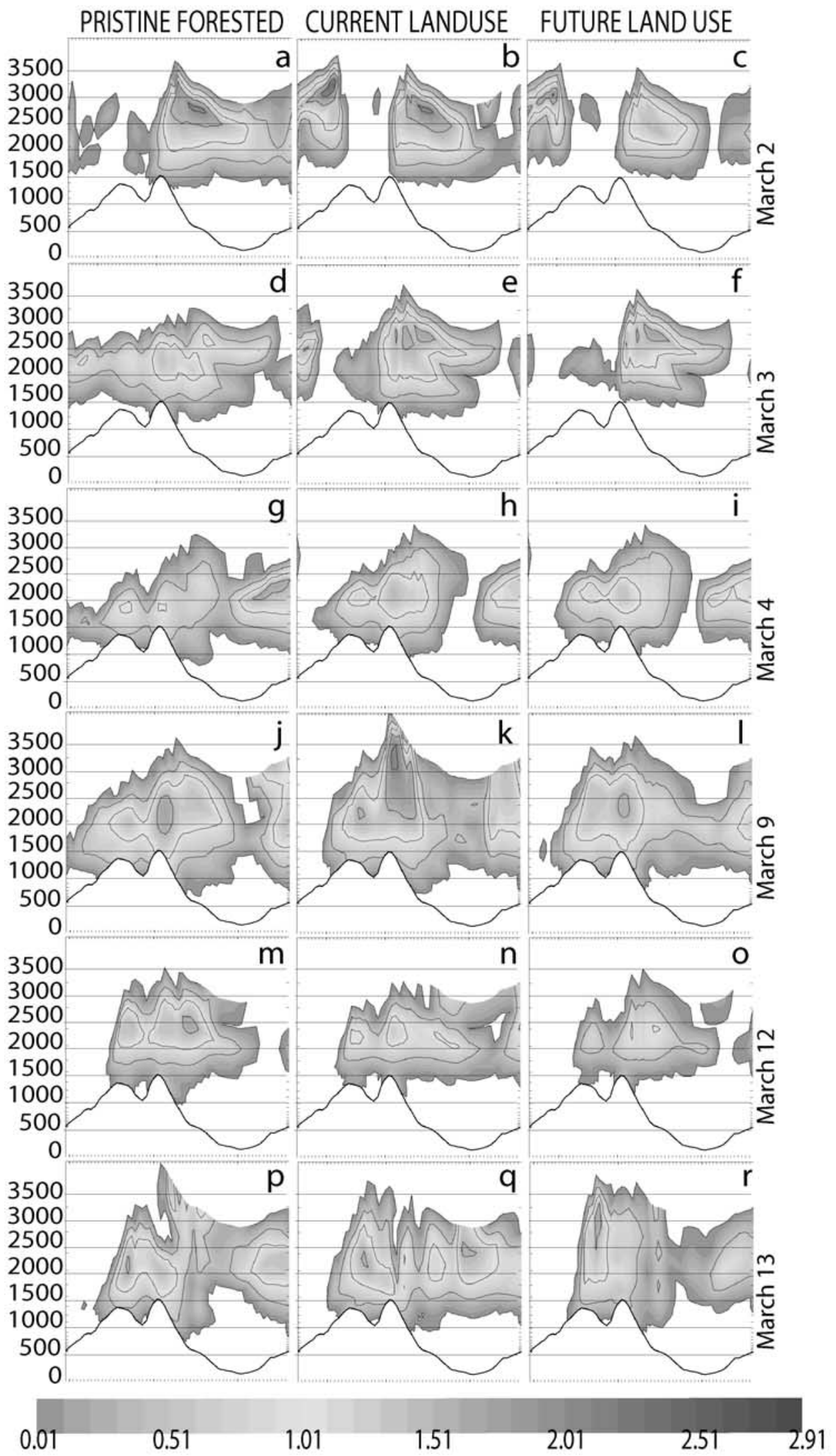

Figure 5. $(\mathrm{a}-\mathrm{r})$ Cross sections of the cloud banks (cloud water mixing ratio in $\mathrm{g} / \mathrm{kg}$ ) intersecting the topography at 1430 LT for the 6 best days of model performance for the three different lowland land use scenarios. 

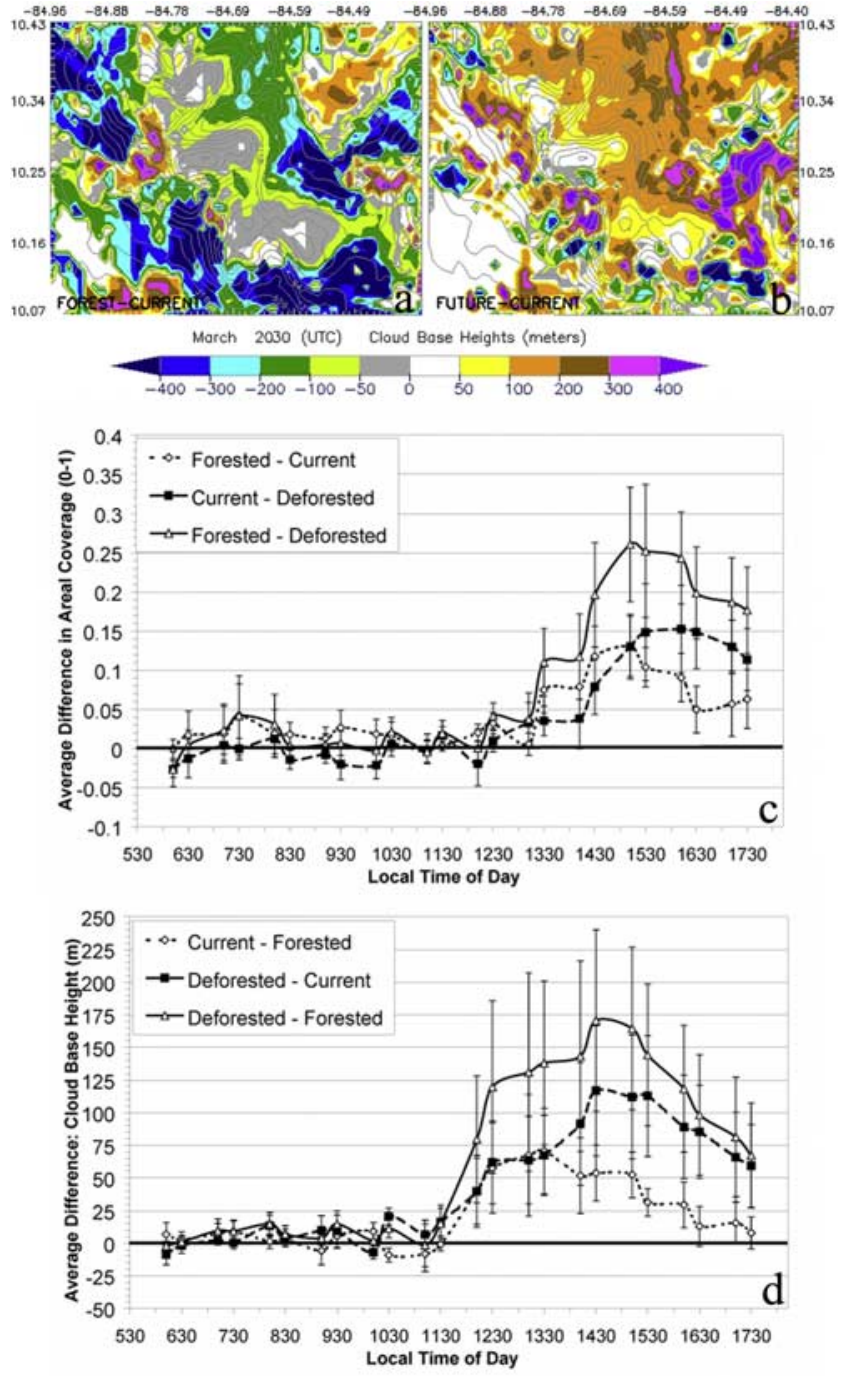

Figure 6. (a) Difference in cloud base heights between the two scenarios: forested/pristine minus current (denoted as forest-current) at 2030 (UTC) (1430 LT). (b) Same as Figure 6a except deforested/future minus current (denoted as future-current). (c) Impact of lowland deforestation on the area covered by fog on the ground at Monteverde. (d) Difference in cloud base height at Monteverde. Note that the difference in Figure 6d is reversed compared to Figure $6 \mathrm{c}$ to show that cloud base rises with deforestation. Bars in Figures $6 \mathrm{c}$ and $6 \mathrm{~d}$ show the standard error $(\mathrm{SE})$ in the estimation of the mean.

vated areas that remain forested in all three land use scenarios. At a model grid cell, cloud immersion at the surface is assumed if nonzero values of liquid water content are present in lowest model level, which is $9 \mathrm{~m}$ above ground and thus well within the forest canopy at most sites.

[37] These cloud immersed highland forests have similar areal extents of cloud immersion during early morning and late evening in all three land use scenarios, but they differ significantly during the late morning and afternoon hours (Figure 6c). The area of highland forests subject to cloud immersion decreases during the morning hours in all the three land use scenarios. During the afternoon hours high- land forests in the completely forested scenario experience significantly more cloud immersion than those either in the current or the deforested land use scenarios. The numerical simulations show that lowland and premontane deforestation has the potential to change how frequently the highland cloud forests experience cloud immersion, the defining characteristic of the cloud forest ecosystems. Between the forested and current scenario, there is a decrease of 5-13\% in the cloud forest area covered by fog, and those between the current and future scenario shows decreases of up to $15 \%$ in the cloud forest area covered with fog. Thus between the two model scenarios of completely forested and complete lowland and premontane deforestation, up to $25 \%$ of the cloud forest area could experience mist free conditions.

\subsubsection{Diurnal Variation of Cloud Base Heights}

[38] The difference in the diurnal variation of averaged cloud base heights over the highland forest regions (Figure 6d) mirrors the observed diurnal pattern of cloud immersion. The averaged cloud base heights in the three land use scenarios do not differ significantly during the morning hours, but during the afternoon hours they show significant differences. Spatially the cloud base heights increase during the morning hours, reaching peak differences amongst the three land use scenarios between 1330 and 1530 LT and then decreases steadily (figures not shown). From approximately 0900 LT onward, a consistent pattern emerges in which the completely forested scenario exhibits the lowest cloud base heights spatially, followed by the current and deforested scenarios, respectively. The maximum differences in cloud base heights between current and forested scenario (current around $75 \mathrm{~m}$ higher) occurs at around $1330 \mathrm{LT}$ (Figure 6d) when the average cloud base heights are approximately 1385 , 1450 , and $1535 \mathrm{~m}$ for the completely forested, current and deforested/future scenarios, respectively. Between the lowland and premontane deforested and current scenario the maximum difference takes place an hour later at 1430 LT (Figure 6d) and is around $125 \mathrm{~m}$. In general after $1430 \mathrm{LT}$, the difference in average cloud base height (Figure 6d) between the completely forested, current and deforested/future scenarios remains positive indicating that deforestation in the lowland and premontane regions has led to the rise in orographic cloud base heights and further deforestation would lead to further increases.

\subsection{Impact on Temperature}

[39] The nature of land use in the Atlantic and Pacific lowland and premontane regions modulates both the air temperature and dew point temperatures, because of changes in surface energy fluxes. In general deforestation raises the air temperatures and lowers the dew point temperatures in the atmosphere over the lowland and premontane regions. Interestingly, Van der Molen et al. [2006] report warmer and drier air over Pterocarpus swamp forest than over tall grass pasture in coastal Puerto Rico. This is because the swamp forest had higher albedo, higher sensible heat flux, and lower latent heat flux than did the pasture. In short, the relative patterns of energy flux were opposite to those reported in most tropical forest - pasture comparisons [Gash and Nobre, 1997]. However, the consequences of the altered surface energy budgets for the overlying atmosphere in our simulations and those of Van der Molen et al. [2006] 
are in agreement. Furthermore, when these modified air masses from the Costa Rican lowlands rise up the Caribbean slopes toward the continental divide they remain distinct in terms of their air temperatures and dew point temperatures.

[40] The spatial patterns of modeled 6-day averages of air temperature at $1400 \mathrm{LT}$ were examined. In the completely forested scenario, the air temperatures in the model inner grid near Monteverde (see Figure 1) varied from around $20^{\circ} \mathrm{C}$ at $0600 \mathrm{LT}$ to peak values of about $24.4^{\circ} \mathrm{C}$ at $1300 \mathrm{LT}$ before decreasing to about $22.5^{\circ} \mathrm{C}$ by $1700 \mathrm{LT}$ (Figure 7a). Deforesting the lowland and premontane regions to their current conditions raised the modeled surface air temperatures in the inner grid. Temperatures change from about $20.3^{\circ} \mathrm{C}$ at $0600 \mathrm{LT}$ to peak values of about $25.4^{\circ} \mathrm{C}$ at $1300 \mathrm{LT}$, then to $23^{\circ} \mathrm{C}$ at $1700 \mathrm{LT}$. Since virtually all of the inner grid below $1000 \mathrm{~m}$ has already been deforested, further deforestation changed modeled temperatures little (Figure 7a). Modeled surface air temperatures in the outer grid (see Figure 1) behaved similarly (Figure 8a), but were warmer, since proportionally more lowlands and the dry Pacific side were included, and further deforestation resulted in greater temperature increases, since portions of the lowlands in the outer grid are currently forested. The lowland and premontane regions were cooler by $1^{\circ} \mathrm{C}$ to $5^{\circ} \mathrm{C}$ at specific locations when completely forested in the past, but averaged values over premontane and lowland regions were cooler by about $1.5^{\circ} \mathrm{C}$ (Figures $7 \mathrm{a}$ and $8 \mathrm{a}$ ). Future deforestation could raise the air temperatures by another $1^{\circ} \mathrm{C}$ to $2^{\circ} \mathrm{C}$ at specific locations, but less than $0.5^{\circ} \mathrm{C}$ over the premontane and lowland regions as a whole.

[41] The 6-day averages of modeled surface dew point temperatures over the premontane and lowland regions in the inner grid were generally higher in the completely forested scenario by up to $1^{\circ} \mathrm{C}$, and lowest in the deforested scenario, but the differences were small between the deforested and the current conditions scenario (Figure 7b). Until 0800 LT the dew point temperatures in the inner grid were nearly identical for the three land use scenarios. However, after $0800 \mathrm{LT}$ the dew point temperatures diverged. Under completely forested conditions the dew point temperatures reached peak values of around $20.4^{\circ} \mathrm{C}$ at $0930 \mathrm{LT}$ and remained at approximately this value until late afternoon. Deforestation to current conditions lowered the dew point temperatures by $0.6^{\circ} \mathrm{C}$ at $0930 \mathrm{LT}$ to $1.1^{\circ} \mathrm{C}$ at $1300 \mathrm{LT}$. Complete deforestation below $1000 \mathrm{~m}$ elevation decreased the dew point temperature by another $0.1{ }^{\circ} \mathrm{C}$ to $0.2^{\circ} \mathrm{C}$. Modeled surface dew point temperatures averaged over the lowland and premontane regions of the outer grid generally behaved similarly (Figure $8 \mathrm{~b}$ ), although dew point temperature differences were greater between the current conditions and further deforestation scenarios, for the reason mentioned above.

\subsection{Impact on Surface Energy Fluxes}

[42] The modeled scenarios suggest that deforestation in the lowland and premontane regions raises sensible heat fluxes and lowers latent heat fluxes. In the completely forested scenario, the sensible heat fluxes in the lowland and premontane regions of the inner grid varied from around $8 \mathrm{Wm}^{-2}$ at $0700 \mathrm{LT}$ to a peak value of $128 \mathrm{Wm}^{-2}$ at $1100 \mathrm{LT}$ and then decreased to around $10 \mathrm{Wm}^{-2}$ at $1700 \mathrm{LT}$, while latent heat flux values ranged from $14 \mathrm{Wm}^{-2}$ at
$0700 \mathrm{LT}$ to around $180 \mathrm{Wm}^{-2}$ at $1200 \mathrm{LT}$ before decreasing to $42 \mathrm{Wm}^{-2}$ at $1730 \mathrm{LT}$ (Figures $7 \mathrm{c}$ and 7d). In comparison, under the current land use scenario, at 0700 LT the sensible heat fluxes were identical to the forested scenario, $90 \mathrm{Wm}^{-2}$ higher at $1100 \mathrm{LT}$ and $29 \mathrm{Wm}^{-2}$ higher at $1700 \mathrm{LT}$, while the latent heat fluxes generally were lower, with the maximum decrease taking place at $1200 \mathrm{LT}$ $\left(104 \mathrm{Wm}^{-2}\right)$. Further deforestation resulted in little further change in the sensible and latent heat fluxes in the inner grid. Modeled sensible and latent heat fluxes averaged over the premontane and lowland regions of the outer grid differed between the completely forested and current conditions scenarios in much the same way, but further deforestation resulted in marked decreases in latent heat fluxes and increases in sensible heat fluxes, due to the fact that proportionately more forest was lost in future deforestation in the outer grid than in the inner (Figures 8c and $8 d$ ). Differences between Figures $7 c, 7 d, 8 c$, and $8 d$ are due largely to the fact that the dry Pacific side is included in the outer grid.

\subsection{Comparisons With Other Studies}

[43] The conclusions of the present study are supported by findings from prior research efforts that also report modulation of cloud base height by surface vegetation. Using measurements obtained from aircraft transects over areas of heterogeneous land use, Schrieber et al. [1996] found lower cloud base heights over irrigated croplands compared to other areas. Freedman et al. [2001] found a significant lowering in lifting condensation level and cloud base height following the spring time vegetation green-up phase in the eastern United States. Large Eddy Simulation (LES) experiments by Golaz et al. [2002] show decreasing cloud base height in response to increasing surface soil moisture or decreasing Bowen Ratio.

[44] The conclusions of the current study may appear contradictory to the models of Van der Molen [2002] which reports decreases in cloud base height if the coastal forests are converted to well watered pastures in Puerto Rico. The apparent contradictions between our model results and those of Van der Molen et al. [2006] are due to the fact that at the Puerto Rican field site the pastures are on very wet sites, and are well watered even in the dry season, and the forests are coastal swamp forests, which may have brackish soils. As a result, the forests had 14\% lower evaporation, and greater sensible heat fluxes, than pastures [Van der Molen, 2002]. In contrast, in Costa Rica, the forests have access to deeper layer soil water, while pasture does not. As a result, while deforestation in Costa Rica results in increases in sensible heat fluxes and decreases in latent heat fluxes (drying effect in response to deforestation) in Puerto Rico higher sensible heat fluxes were found over forests compared to the well watered pastures (moistening effect with deforestation). Scatena and Larsen [1991] and Bruijnzeel and Hamilton [2000] also reported results that would appear contradictory to those of Van der Molen [2002] and Bruijnzeel [2004] discusses identical reasons for these differences. In essence both the present study and Van der Molen [2002] show that the nature of land use upwind of orographic cloud formation alters the base height of orographic cloud banks. The cloud banks are elevated if the overall effect of the land use change is an increase in Bowen ratio as reported in the 


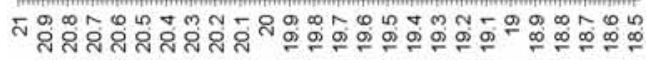

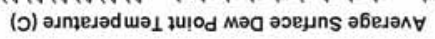

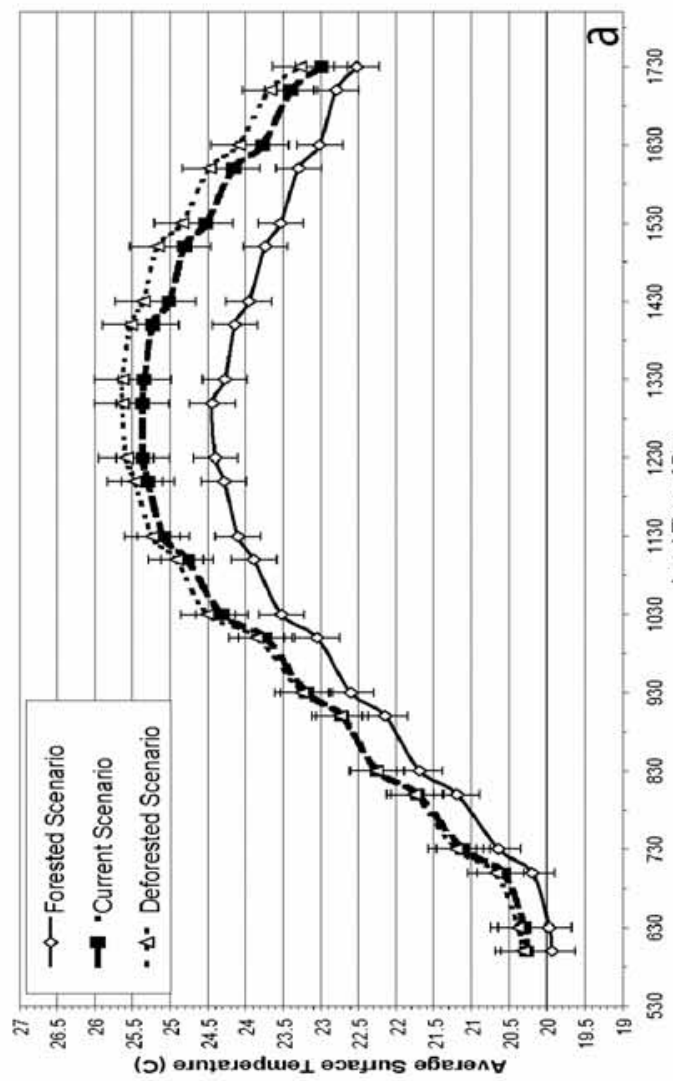

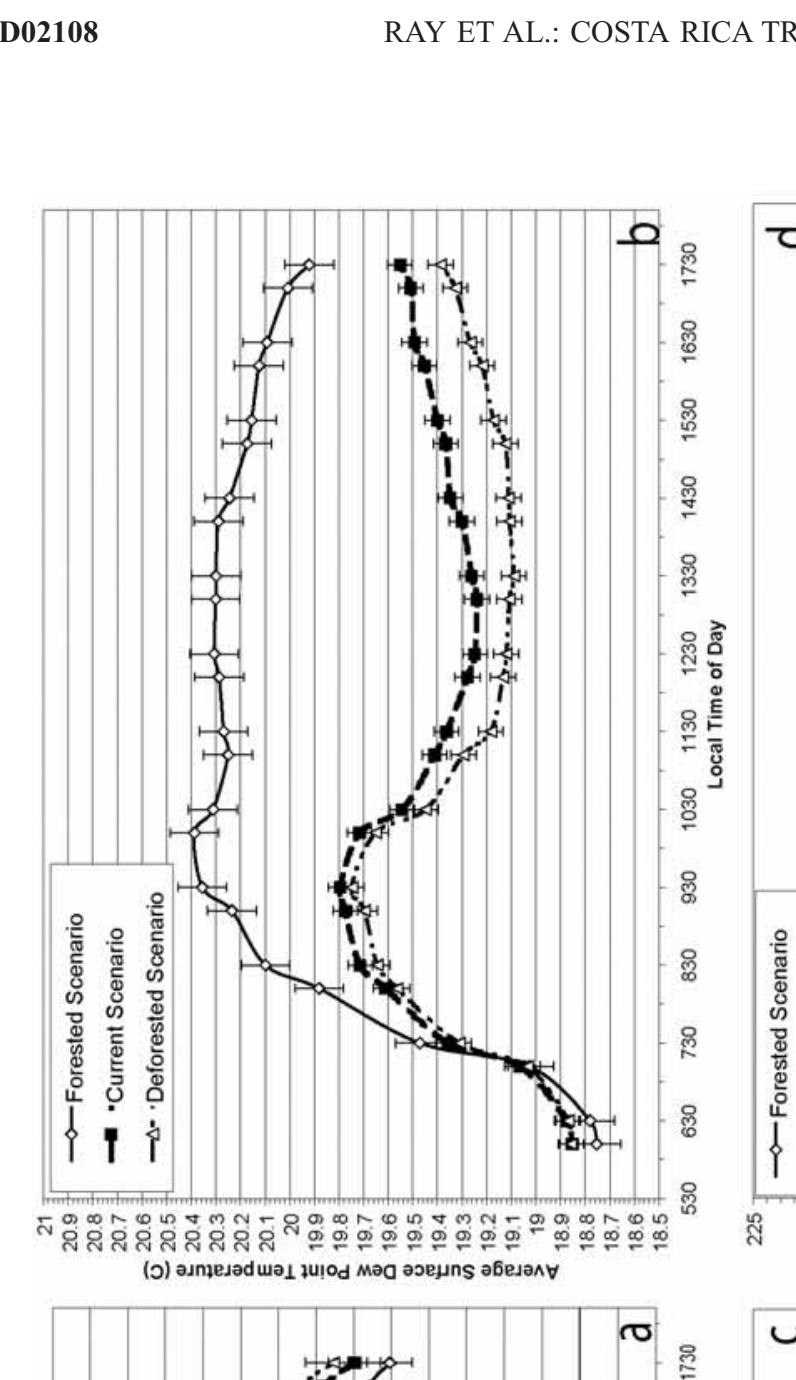

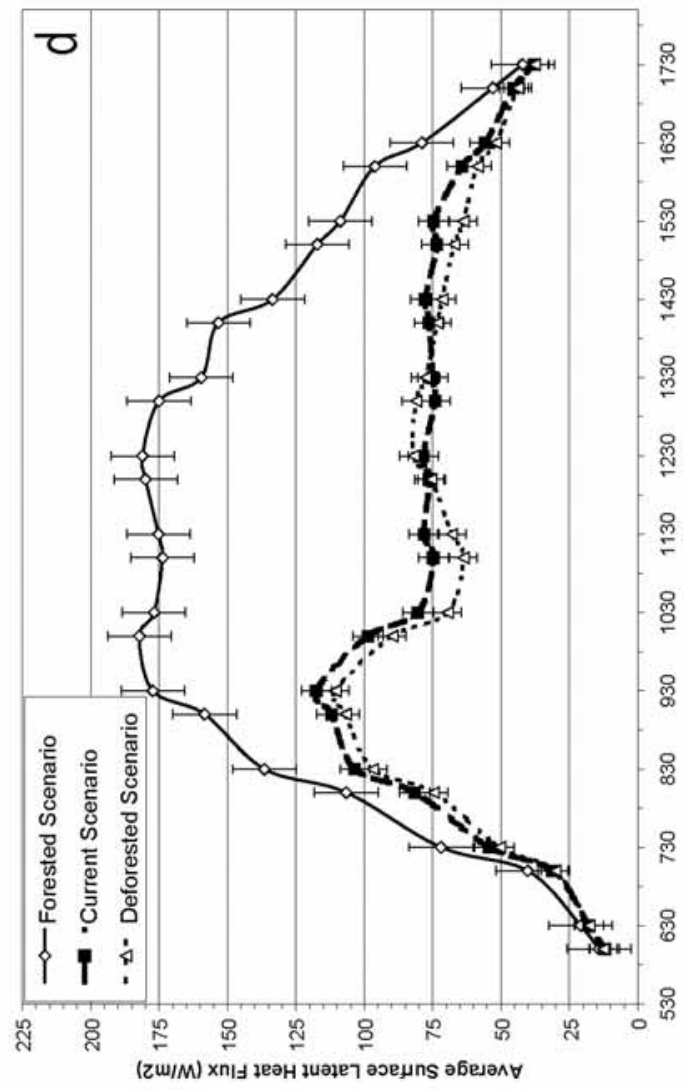

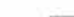

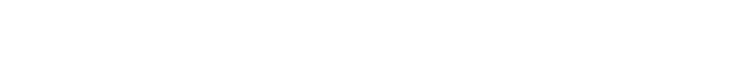

品

䓪

ब苛

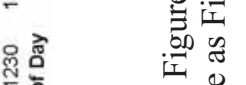

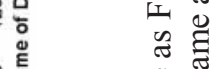

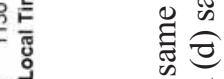

高要

羟

(⿻)

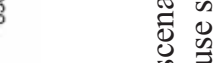

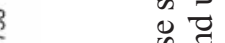

要焉

过

过

을

荧

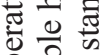

일 क्षे

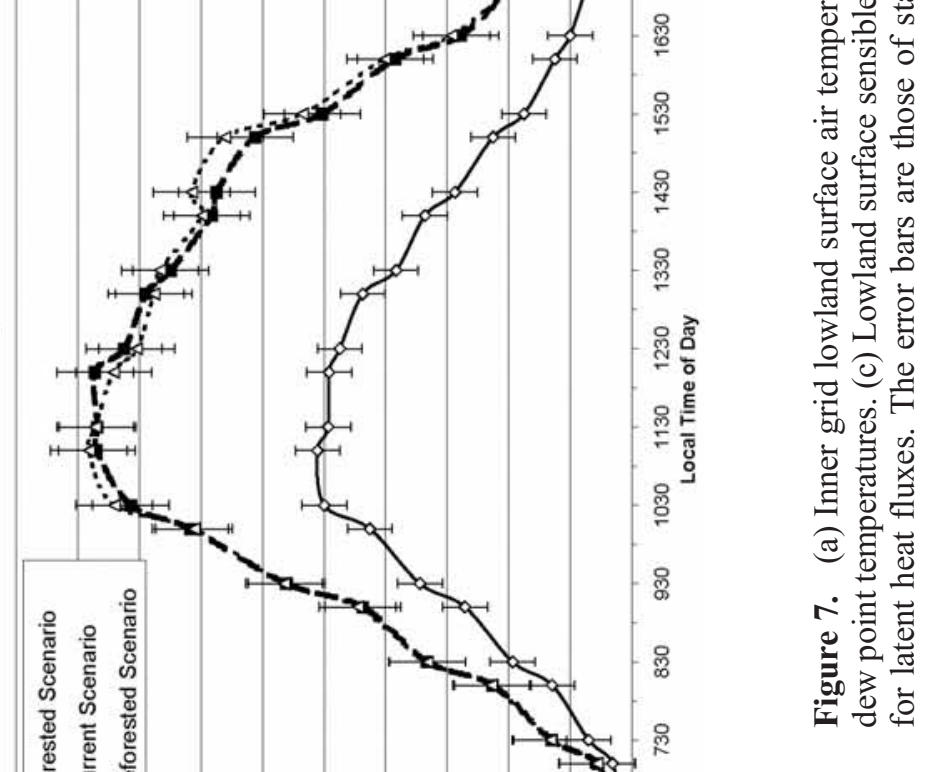




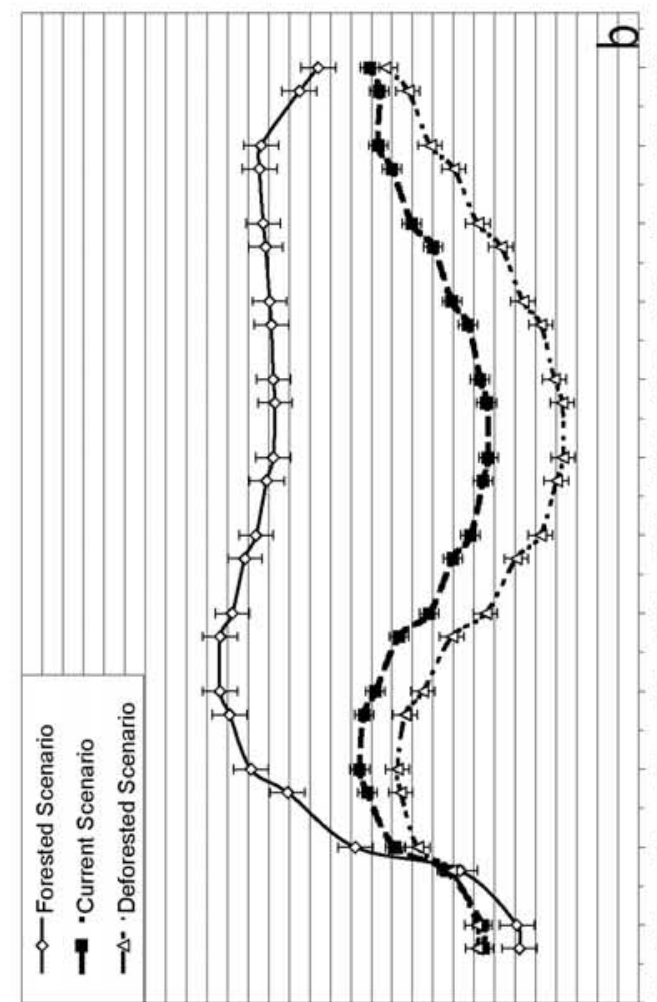

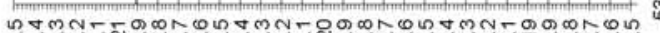

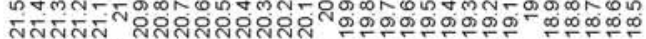

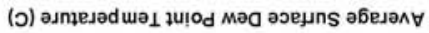

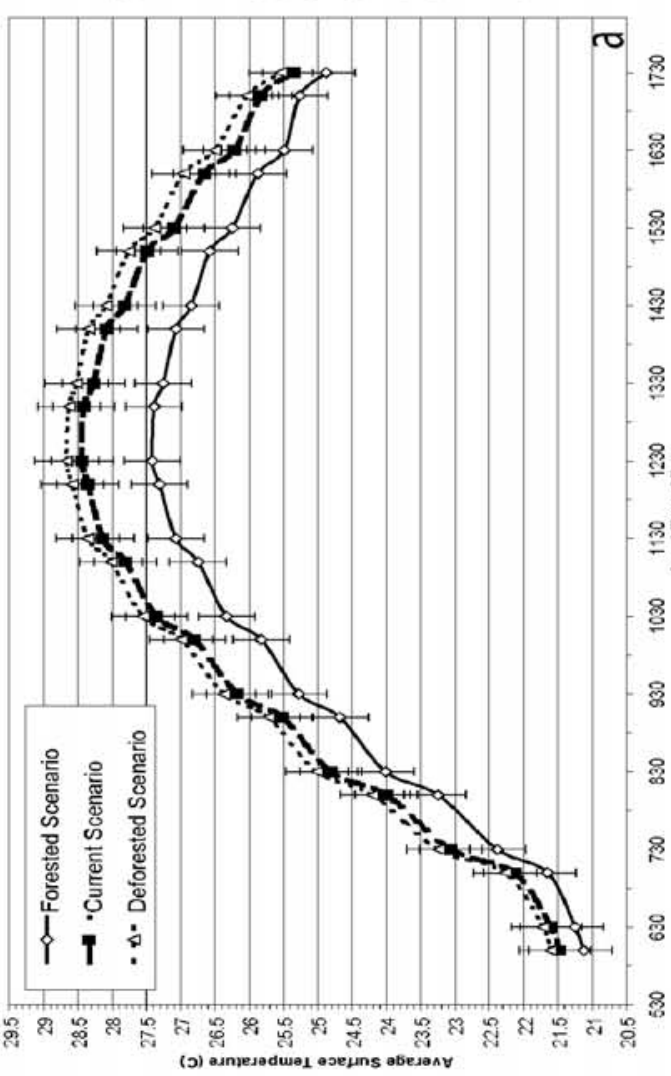

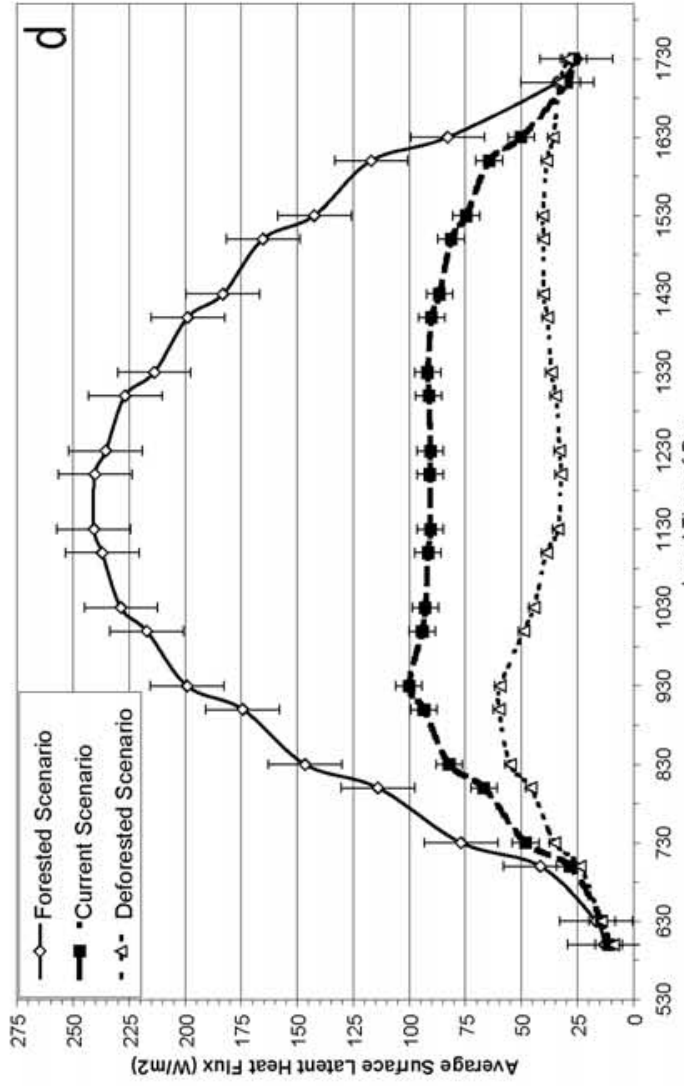

(
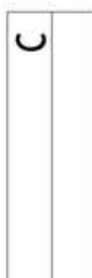
present study, while the opposite is true if the Bowen ratio is decreased as a result of the land use change as reported in work of Van Der Molen [2002].

\section{Conclusions}

[45] Tropical montane cloud forests occupy approximately $0.4 \%$ of the Earth's surface, and yet they support about $20 \%$ and $16 \%$ of the planet's plant and vertebrate diversity, respectively. The characteristic feature of these forests is frequent immersion in clouds. In the dry season these forests directly intercept moisture from the clouds, accounting for $15-100 \%$ of the total precipitation [Bruijnzeel and Proctor, 1993]. If cloud bases over these forests rise, this source of moisture input would be cut off, altering the character of local ecological communities, and consequently the geographic distribution of cloud forests [Lawton et al., 2006]. Both the local and regional changes threaten to increase the rate of extinction of cloud forest species.

[46] Many cloud forests around the world are now threatened for a variety of reasons. The Monteverde cloud forest in Costa Rica is well protected, and yet it has recently seen population crashes of anurans, migration of birds to higher elevations, and extinction of amphibians such as the golden toads. Still et al. [1999] and Pounds et al. [1999] argued that increased sea surface temperatures are responsible for the rising cloud bases at the Monteverde cloud forests. Lawton et al. [2001] and Nair et al. [2003], however, concluded that lowland deforestation in the Caribbean and Pacific plains is responsible for drying the air masses, consequently leading to rising bases of the orographic clouds intersecting the mountain range. Through numerical modeling using the CSU RAMS, they showed that cloud base heights increase if forests are converted to pastures.

[47] The current study also utilizes the CSU RAMS to investigate cloud base heights over the cloud forests of Monteverde in response to land use changes in the Caribbean and Pacific lowlands, but offers more realistic land use scenarios. Moreover, soil moisture values measured in the study area were used to initialize the model. A blended analysis of rawinsondes (launched during the LUCIE field campaign) and a variety of satellite data sets also were used to drive the model.

[48] The RAMS simulations include 14 days (1-14 March 2003), and the clouds simulated by the model for the current conditions were compared with the GOES observed clouds for these 14 days. It was found that the model performed best ( 0900 LT to 2200 LT) for 6 out of these 14 days. The simulated atmospheric profiles also were compared with those from rawinsondes, and it was found that below $700 \mathrm{mb}$ the two profiles matched very well, thereby increasing the confidence in the simulation of lowlevel orographic clouds. These 6 days were then analyzed in detail.

[49] As lowland deforestation progresses, the montane area immersed in orographic cloud progressively decreases. The impact is greatest in the afternoon hours. There is a 5$13 \%$ decrease in areal coverage between the forested and current scenario and decreases of up to $15 \%$ can take place if there is further deforestation in the lowland and premontane regions. The montane cloud base heights also increase with lowland deforestation; increases of up to around $75 \mathrm{~m}$ between the forested and current conditions and up to around $125 \mathrm{~m}$ between current and lowland and premontane deforestation. On the basis of these analyses we project a cloud free condition to persist between 1 to 4 hours at elevations of $1450 \mathrm{~m}$ to nearly $1550 \mathrm{~m}$ in the afternoon hours if the lowland and premontane regions are further deforested. The cloud free conditions are projected to occur because lowland and premontane deforestation increases the air temperature and sensible heat fluxes and decreases the dew point temperatures and latent heat fluxes of the air masses that ultimately rise to form the orographic clouds over cloud forests. Further lifting of cloud base heights in the future deforestation scenario would significantly reduce dry season horizontal precipitation and create much drier conditions at these elevations, presumably leading to large loss of biodiversity in the area.

[50] Acknowledgments. This project was supported through NASA grant NAG5-11941 and NSF grant ATM-0128924. Deepak K. Ray was supported by a NASA Earth System Science Fellowship.

\section{References}

Bruijnzeel, L. A. (2004), Hydrological functions of tropical forests: Not seeing the soil for the trees?, Agric. Ecosyst. Environ., 104, 185-228.

Bruijnzeel, L. A., and L. S. Hamilton (2000), Decision time for cloud forests, IHP Humid Tropics Program Ser. 13, 41 pp., Int. Hydrol. Programme, U.N. Educ., Sci., and Cult. Organ., Paris.

Bruijnzeel, L. A., and J. Proctor (1993), Hydrology and biogeochemistry of tropical montane cloud forests: What do we really know?, in Tropical Montane Cloud Forests: Proceedings of an International Symposium, edited by L. S. Hamilton, J. O. Juvik, and F. N. Scatena, pp. 25-46, East-West Cent., Honolulu.

Bruijnzeel, L. A., and J. Proctor (1995), Hydrology and biogeochemistry of tropical montane cloud forest: What do we really know?, Ecol. Stud., 110, $8-31$.

Carlson, T. N., and G. A. Sanchez-Azofeifa (1999), Satellite remote sensing of land use changes in and around San Jose, Costa Rica, Remote Sens. Environ., 70, 247-256.

Cavelier, J., D. Solis, and M. A. Jaramillo (1996), Fog interception in montane forest across the central cordillera of Panama, J. Trop. Ecol., $12,357-369$

Clark, K. L., R. O. Lawton, and P. R. Butler (2000), The physical environment, in Monteverde: Ecology and Conservation of a Tropical Cloud Forest, edited by N. Nadkarni and N. Wheelwright, pp. 15-38, Oxford Univ. Press, New York.

Doumenge, C., D. Gilmour, M. R. Perez, and J. Blochus (1995), Tropical montane cloud forests: Conservation status and management issues, in Tropical Montane Cloud Forests, edited by L. S. Hamilton, J. O. Juvik, and F. N. Scatena, pp. 24-37, Springer, New York.

Food and Agriculture Organization (1971), Soil map of the world, scale 1:5,000,000, vol. II-X, U.N. Educ., Sci., and Cult. Organ., Paris.

Freedman, J. M., D. R. Fitzjarrald, K. E. Moore, and R. K. Sakai (2001), Boundary layer clouds and vegetation-atmosphere feedbacks, J. Clim., $14,180-197$.

Gash, J. H. C., and C. A. Nobre (1997), Climatic effect of Amazonian deforestation: Some results from ABRACOS, Bull. Am. Meteorol. Soc., $78,823-830$.

Gerakis, A., and B. Baer (1999), A computer program for soil textural classification, Soil Sci. Soc. Am. J., 63, 807-808

Golaz, J. C., H. Jiang, and W. R. Cotton (2002), A large-eddy simulation study of cumulus clouds over land and sensitivity to soil moisture, Atmos. Res., 59, 373-392.

Gomez, L. D. (1986), Vegetacion de Costa Rica, in Vegetación y Clima de Costa Rica, vol. 1, edited by L. D. Gomez, Univ. Estatal a Distancia, San José, Costa Rica.

Haeger, A., and A. Dohrenbusch (2004), Effects of leeward and windward positions on a tropical mountain ridge on climate and soil water conditions, paper presented at 2nd International Cloud Forest Symposium: Mountains in the Mist-Science for Conserving and Managing TMCF, U. N. Educ., Sci., and Cult. Organ., Waimea, Hawaii, 27 July to 1 Aug.

Hamilton, L. S., J. O. Juvik, and F. N. Scatena (1993), The Puerto Rico tropical cloud forest symposium: Introduction and workshop synthesis, in Tropical Montane Cloud Forests, edited by L. S. Hamilton, J. O. Juvik, 
and F. N. Scatena, pp. 1-16, East-West Cent. Program on Environ., Honolulu.

Hansen, M. C., R. S. DeFries, J. R. G. Townshend, and R. Sohlberg (2000), Global land cover classification at the $1 \mathrm{~km}$ spatial resolution using a classification tree approach, Int. J. Remote Sens., 21, 1331-1364.

Harrington, J. Y., and P. Q. Olsson (2001), A method for the parameterization of cloud optical properties in bulk and bin microphysical models Implications for Arctic cloudy boundary layers, Atmos. Res., 57, 51-80.

Holdridge, L. R. (1967), Life Zone Ecology, rev. ed., Trop. Sci. Cent., San Jose, Costa Rica.

Kalnay, E., et al. (1996), The NCEP/NCAR 40-year reanalysis project, Bull. Am. Meteorol. Soc., 77, 437-471.

Kerfoot, O. (1968), Mist precipitation on vegetation, For. Abstr., 29, 8-20.

Klemp, J. B., and R. B. Wilhelmson (1978), The simulation of three-dimensional convective storm dynamics, J. Atmos. Sci., 35, 1070-1096.

Knyazikhin, Y., J. V. Martonchik, R. B. Myneni, D. J. Diner, and S. W. Running (1998), Synergistic algorithm for estimating vegetation canopy leaf area index and fraction of absorbed photosynthetically active radiation from MODIS and MISR data, J. Geophys. Res., 103, 32,25732,275 .

Lawton, R. O., U. S. Nair, R. A. Pielke, and R. M. Welch (2001), Climatic impact of tropical lowland deforestation on nearby montane cloud forests, Science, 294, 584-587

Lawton, R. O., U. S. Nair, D. K. Ray, A. Regmi, A. Pounds, and R. M Welch (2006), Quantitative measures of immersion in cloud and the biogeography of cloud forest, in Mountains in the Mist: Science for Conserving and Managing Tropical Montane Cloud Forest, edited by L. A. Bruijnzeel et al., Univ. of Hawaii Press, Honolulu, in press.

Mahrer, Y., and R. A. Pielke (1975), A numerical study of air flow over mountains using the two-dimensional version of the University of Virginia mesoscale model, J. Atmos. Sci., 32, 2144-2155.

Meher-Homji, V. M. (1991), Probable impact of deforestation on hydrological processes, Clim. Change, 19, 163-173.

Mellor, G. L., and T. Yamada (1982), Development of a turbulence closure model for geophysical fluid problems, Rev. Geophys., 20, 851-875.

Myers, N., R. A. Mittermier, C. G. Mittermier, G. A. B. da Fonesca, and J. Kent (2000), Biodiversity hotspots for conservation priorities, Nature, $403,853-858$

Myneni, R. B., R. R. Nemani, and S. W. Running (1997), Estimation of global leaf area index and absorbed PAR using radiative transfer model, IEEE Trans. Geosci. Remote Sens., 35, 1380-1393.

Nair, U. S., J. A. Rushing, R. Ramachandran, K. S. Kuo, R. M. Welch, and S. J. Graves (1999), Detection of cumulus cloud fields in satellite imagery, in Earth Observing Systems IV, edited by W. L. Barnes, Proc. SPIE Int Soc. Opt. Eng., 3750, 345-355.

Nair, U. S., R. O. Lawton, R. M. Welch, and R. A. Pielke Sr. (2003), Impact of land use on Costa Rican tropical montane cloud forests: Sensitivity of cumulus cloud field characteristics to lowland deforestation, J. Geophys. Res., 108(D7), 4206, doi:10.1029/2001JD001135.

Nepstad, D. C., C. R. de Carvalho, E. A. Davidson, P. H. Jipp, P. A. Lefebvre, G. H. Negreiros, E. D. da Silva, T. A. Stone, S. E. Trumbore, and S. Vieira (1994), The role of deep roots in the hydrological and carbon cycles of Amazonian forests and pastures, Nature, 372, 666669.

Pielke, R. A., et al. (1992), A comprehensive meteorological modeling system-RAMS, Meteorol. Atmos. Phys., 49, 69-91.

Pounds, A. J., M. P. L. Fogden, and J. H. Campbell (1999), Biological response to climate change on tropical mountain, Nature, 389, 611-614.

Reiners, W. A., S. Liu, K. G. Gerow, M. Keller, and D. S. Schimel (2002), Historical and future land use effects on $\mathrm{N}_{2} \mathrm{O}$ and $\mathrm{NO}$ emissions using an ensemble modeling approach: Costa Rica's Caribbean Lowlands as an example, Global Biogeochem. Cycles, 16(4), 1068, doi:10.1029/ $2001 \mathrm{~GB} 001437$.

Sader, S. A., and A. T. Joyce (1988), Deforestation rates and trends in Costa Rica, 1940 to 1983, Biotropica, 20, 11-19.

Scatena, F. N., and M. C. Larsen (1991), Physical aspect of hurricane Hugo, Biotropica, 23, 317-323.

Schrieber, K., R. Stull, and Q. Zhang (1996), Distributions of surface-layer buoyancy versus lifting condensation level over a heterogeneous land surface, J. Atmos. Sci., 53, 1086-1107.

Still, C. J., P. N. Foster, and S. H. Schneider (1999), Simulating the effects of climate change on tropical montane cloud forests, Nature, 389, 608610 .

Tremback, C. J., and R. Kessler (1985), A surface temperature and moisture parameterization for use in mesoscale numerical models, paper presented at 7th AMS Conference on Numerical Weather Prediction, Am. Meteorol. Soc., Montreal, Que., Canada, 17-20 June.

Van der Molen, M. K. (2002), Meteorological impacts of land use change in maritime tropics, Ph.D. thesis, Vrije Univ., Amsterdam, Netherlands.

Van der Molen, M. K., H. F. Vugts, L. A. Bruijnzeel, F. N. Scatena, R. A. Pielke Sr., and L. J. M. Kroon (2006), Mesoscale climate change due to lowland deforestation in the maritime tropics, in Mountains in the Mist: Science for Conserving and Managing Tropical Montane Cloud Forest, edited by L. A. Bruijnzeel et al., Univ. of Hawaii Press, Honolulu, in press.

Veldkamp, E., A. M. Weitz, I. G. Staritsky, and E. J. Huising (1992), Deforestation trends in Atlantic zone of Costa Rica: A case study, Land Degrad. Rehabil., 3, 71-84.

Walko, R. L., et al. (2000), Coupled atmosphere-biophysics-hydrology models for environmental modeling, J. Appl. Meteorol., 39, 931-944.

Webb, R. W., C. E. Rosenzweig, and E. R. Levine (1992), A global data set of soil particle size properties, NASA Tech. Memo. TM-4286.

Wheelwright, N. T. (2000), Monteverde: Ecology and Conservation of a Tropical Cloud Forest, edited by N. M. Nadkarni and N. T. Wheelwright, pp. 419-456, Oxford Univ. Press, New York.

R. O. Lawton, Department of Biological Sciences, University of Alabama in Huntsville, Huntsville, AL 35899, USA

U. S. Nair, D. K. Ray, and R. M. Welch, Department of Atmospheric Science, National Space Science and Technology Center, University of Alabama in Huntsville, Huntsville, AL 35806, USA. (ray@nsstc.uah.edu)

R. A. Pielke Sr., Department of Atmospheric Science, Colorado State University, Fort Collins, CO 80523-1371, USA. 